\title{
Using Digital Technologies to Improve the Efficiency of Discussion Environments for Economics Students During COVID-19
}

\author{
Askadula Sabirov, Kazan Federal University, Russia* \\ Fariza Aituganovna Ismagambetova, L.N. Gumilyov Eurasian National University, Kazakhstan \\ Alexander Leonidovich Yurchenko, Financial University Under the Government of the Russian Federation, Russia
}

\begin{abstract}
The article is devoted to studying the impact of digital technologies on providing an efficient educational discussion environment against the background of isolation and social distancing caused by COVID-19 preventive measures. The course structuring allowed fostering a better understanding of educational activities. The use of popular online communication tools positively influenced educational communication effectiveness. The conscious attitude to training facilitated the formation of a corporate culture of engagement in the learning environment. Thematic and consulting support provided by academic assistants allowed forming a sense of confidence. The implementation of the concept of business gamification provoked an increase in students' interest in practical training and entailed greater participation in learning. The relevance of the creative work topic enabled students to express their own view on professional activity and reinforced the desire for using the gained knowledge and experience in practice.
\end{abstract}

\section{KEYWORDS}

Digital Platforms and Tools, Discussion Environment, E-Learning, Effectiveness of Online Practices, Functional and Physical Readiness

\section{INTRODUCTION}

The sudden outbreak of the COVID-19 has led to the immediate closure of schools, colleges, and universities. Educational institutions worldwide have shifted from traditional teaching methods to e-learning as the introduction of isolation and social distancing was enforced as a preventive measure against the spread of coronavirus infection. In these conditions, e-learning has proven to be an essential tool for delivering effective education during isolation (Soni, 2020). It is often referred to as a general concept of online teaching and learning with technological tools and platforms providing a wide range of applications and processes for implementing learning practices (Abbas et al., 2005). The widespread use of technology, constantly updated information, the need for open access to educational resources and training individualization have resulted in a profound shift in pedagogical approaches. Wireless technologies and mobile devices acquired a prominent role in popularizing the concepts of distance, online, and mobile learning (Talan, 2020). 
Advanced technologies provide innovative and sustainable solutions to tackle disruption during crises and help people communicate and work virtually without the need for face-to-face contact. This leads to many systemic changes in organizations as they adopt new technologies to interact and work (Mark \& Semaan, 2008). Educational institutions are introducing e-learning with the aim of improving teacher-student communication, facilitating effective knowledge exchange, and developing interaction in the learning environment to accomplish educational objectives (Basak et al., 2016). Mobile technologies are able to give immediate access to unlimited information from anywhere and anytime through specially developed applications. They allow students to interact with information easily and enable technology for educational purposes (Talan, 2020). The process of training often benefits from various internet-based technological tools distributed via the web (Muhammad et al., 2016; Zhigareva et al., 2019). In this day and age, digital educational technologies have become more ubiquitous than ever. They offer flexible opportunities promoting convergence and creativity as well as open up new forms and models of organizing and managing educational processes (Chien et al., 2020; Vorbach et al., 2019).

The social distancing has provoked the urgent need for more widespread use of online platforms and digital tools that create remote education opportunities. E-learning platforms can help education providers manage, plan, deliver and track the learning and teaching process. Factors affecting their effectiveness include those related to technological issues, e-learning system quality, culture, selfefficacy, and trust (Almaiah et al., 2020). In the meantime, the overall success of e-learning depends on internet connection quality, learning software, digital skills, and availability and access to technology.

Given the current situation, e-learning systems remain vital to support inclusive and distance education (Onyema et al., 2020). E-learning encourages students to work together, develop their academic competence, improve self-efficacy and promote social and cognitive skills (Ngai et al., 2019). It is no question that e-learning brings positive results, but its final outcome depends on the context (Adarkwah, 2021). In this connection, the planning of e-learning scenarios is an absolute must for academic institutions (Rieley, 2020). Well-designed personalized technology-aided learning programs can significantly increase hands-on training productivity (Muralidharan et al., 2019). The effective use of digital technologies should be driven by learning and teaching goals rather than a specific technological function that does not in itself lead to increased attainment (Azevedo et al., 2021).

Given the currently limited teacher-student communication capabilities caused by COVID-19 preventive measures, the introduction of adequate technological tools, as well as innovative teaching styles and methodologies, is represented as a key demand to support high-quality training in higher education institutions. In this regard, the purpose of the study is to investigate the impact of digital technologies on the efficiency of educational discussion environment during global isolation and social distancing. To achieve this goal, the following tasks were set:

- develop a Digital Technologies and Management e-learning course on the basis of Within the framework of bachelor's degree programs of the L.N. Gumilyov Eurasian National University (Kazakhstan), Kazan Federal University (the Russian Federation) and the Financial University under the Government of the Russian Federation (the Russian Federation);

- Conduct an educational experiment (September-December, 2020) using a web-based learning management system (Canvas), online communication tools (Viber Messenger, Runkeeper), and a social network (Facebook);

- Develop and test the concept of gamification within the practical part of the course;

- Assess the observance and implementation of the principles of the educational course at all training stages;

- Identify factors influencing the efficiency of the educational discussion environment. 


\section{MATERIALS AND METHODS}

Since practical human activity is formed, realized, and limited by combinations of arrangements that compose practice architectures, this particular theory was taken as a basis in developing the concept and structure of the e-learning course (Sjølie et al., 2020). The theory of practice architectures presents practices as comprised of sayings, doings, and ties related to one project, idea, or goal. These three elements are always combined and happen in three dimensions of intersubjective space: (1) semantic space, where we meet each other as interlocutors (the language context); (2) physical space, where we meet each other as embodied beings (in the context of activity and work); and (3) social space, where we meet each other and the world as social beings (in the context of solidarity and power) (Nicolini, 2012). Apart from this, the practices are enabled and constrained by three different types of agreements: (1) cultural-discursive agreements (e.g., languages, discourses), (2) material-economic agreements (e.g., offices, classrooms, digital technologies) and (3) socio-political agreements (e.g., hierarchies, collegial relations, state-university ties) (Kemmis \& Edwards-Groves, 2018).

Modern technological tools and e-learning platforms provide an opportunity to simulate quasiprofessional practical activities in the framework of educational processes, thereby contributing to the effective achievement of educational goals. Popular online communication platforms that are rapidly being introduced into education all around the world include Start.me, Neo, Classtime, Classwize, Ted-Ed, Coursera, Google Classroom, Bakpax, Pronto, Skillshare, ClassDojo, Edmodo, Blackboard Learn, Parlay, Docebo, Feedback Fruits, Udemy, WeVideo, WizIQ, Flipgrid, Codeacademy, Gynzy, Adobe Captivate, Seesaw, Edx, GoGuardian, Elucidat, Kami, Pluralsight, G Suite Otus, Articulate 360, Floop, Future Learn, Hapara, Shift, Lectora Inspire, Kialo Edu, Buncee, and LanSchool (Mishra et al., 2020).

When developing the online course, the task was to achieve the synergy of high-quality training content and technological solutions. Consequently, those technological tools were selected, capabilities of which harmonized with the study goals. Canvas is a web-based learning management system (LMS) used by learning institutions, educators, and students to access and manage online course materials and discuss skills development and academic achievements. Canvas includes a variety of customizable instruments for course creation and management, course and user analytics and statistics, and intragroup communication. It provides curriculum designers and educators with an opportunity to create and share course materials using such tools as Assignments, Discussions, Modules, Quizzes, and Pages. Aside from this, Canvas enables fostering collaborative learning by means of Collaborations, Conferences, and Groups. Depending on course settings, students can access these areas in Canvas to find learning materials and interact with other course users. Provided that Canvas is originally web-based, any user can access this LMS on a mobile device from the Canvas Teacher, Canvas Student, or Canvas Parent applications (Canvas, 2020). Viber is a popular free online service for sending individual or group text messages and making audio and video calls (Rakuten Viber, 2020). Runkeeper is a cross-platform application that allows planning, making, and assessing the physical activity in order to ensure the desired level of functional and physical readiness to achieve life goals (ASICS Runkeeper, 2020). Facebook was used as the largest social network in the world, offering many functions for mutual interaction. It allows sharing photos, text messages, videos, statuses, and comments. For many users, visiting Facebook has become a part of daily routine (Facebook, 2020).

\subsection{Research Design and Sample}

The educational experiment involved 250 students of the L.N. Gumilyov Eurasian National University (Kazakhstan), Kazan Federal University (the Russian Federation), and the Financial University under the Government of the Russian Federation (the Russian Federation). Relevant data on the research participants are presented in Table 1 and Figure 1. The main selection criteria were the course and specialty of students. The main selection criteria were the course and specialty of the students, age or gender characteristics were not taken into account. Probable respondents were e-mailed invitations 
to participate in the experiment. After the answer was received, we analyzed the questionnaires of all students and selected those that meet the sampling criteria.

The study process implied holding a joint e-learning course named Digital Technologies and Management as part of a bachelor's degree program. The course was supposed to use the capabilities of a learning management system (Canvas), mobile applications (Viber Messenger and Runkeeper), a social network (Facebook) and last for four months (from September to December 2020).

\section{Table 1. Research participants}

\begin{tabular}{|c|c|c|}
\hline $\begin{array}{l}\text { Number of } \\
\text { students }\end{array}$ & Study programs and directions & Educational institution \\
\hline 140 & $\begin{array}{l}\text { 38.04.02 Management: } \\
\text { - Business Analytics; } \\
\text { - Financial Marketing; } \\
\text { - Financial Management and Capital Market; } \\
\text { - Management of Sports Industry; } \\
\text { - Project Management of Public-Private Partnerships; } \\
\text { - Innovation Management and Entrepreneurship; } \\
\text { - Project Management; } \\
\text { - Management and International Business; } \\
\text { - Corporate Governance; } \\
\text { - Crisis Management and Consulting } \\
\text { - Management Consulting }\end{array}$ & \multirow[t]{3}{*}{$\begin{array}{l}\text { Kazan Federal University (the } \\
\text { Russian Federation) } \\
\text { Financial University under the } \\
\text { Government of the Russian } \\
\text { Federation (the Russian } \\
\text { Federation) }\end{array}$} \\
\hline 17 & $\begin{array}{l}\text { 38.04.03 Personnel Management } \\
\text { - Human Resources Management }\end{array}$ & \\
\hline 13 & $\begin{array}{l}\text { 43.04.02 Tourism: } \\
\text { - Sustainable development of the hospitality and tourism industry }\end{array}$ & \\
\hline 50 & 6B04105 - Economics of Entrepreneurship and Business & \multirow{2}{*}{$\begin{array}{l}\text { L.N. Gumilyov Eurasian } \\
\text { National University } \\
\text { (Kazakhstan) }\end{array}$} \\
\hline 30 & 6B04110 - Public administration & \\
\hline & Total: 250 students & \\
\hline
\end{tabular}

Figure 1. Study group characteristics
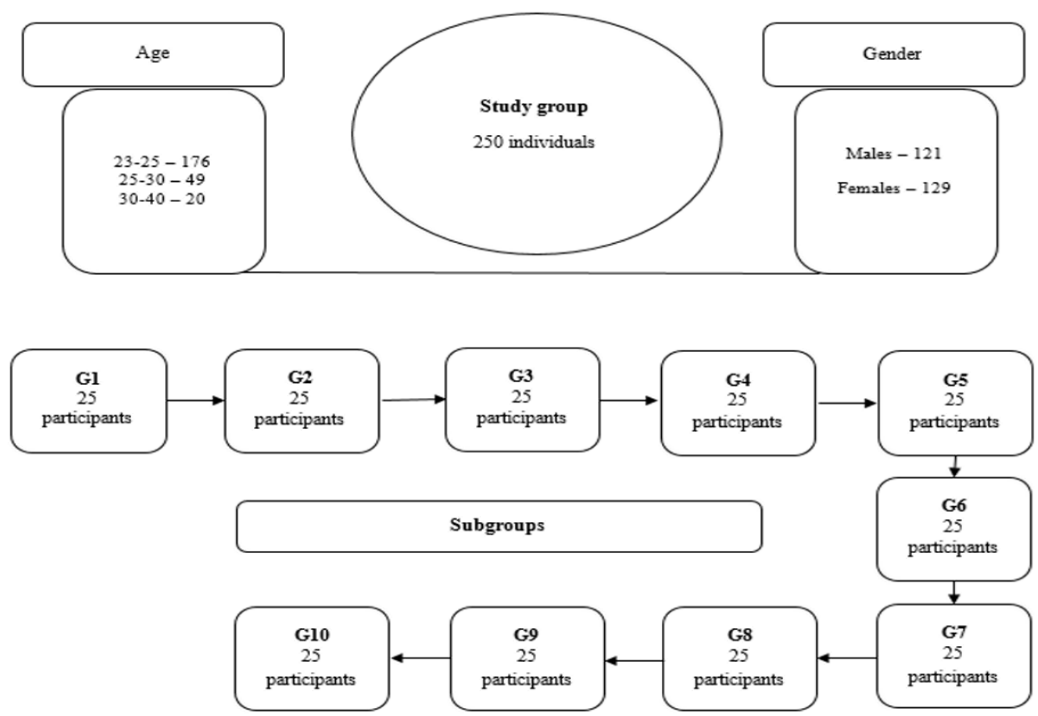
*developed by the authors

The Digital Technologies and Management course was attended by students aged 23 to 40 (121 men and 129 women). The study group of 250 individuals was divided into ten subgroups, 25 people each. The role of training supervisors and advisers was performed by postgraduate students and graduate associates of the considered educational establishments. Each subgroup was assigned one academic adviser, whose functional responsibilities included consultative support in performing practical tasks and providing thematic communication and interaction on digital platforms. At the same time, they were supposed to analyze students' dynamics and activity by subgroups and draw reports on work results.

\subsection{Research Limitations}

Since the study aimed to determine the critical factors for increasing the efficiency of educational discussion environments, it fails to provide a comprehensive assessment of the effectiveness of the training course in general and the impact of the communication component in particular. From the students 'point of view, the course influenced the effectiveness of the considered educational discussion environment, as evidenced by indicators such as students' involvement, activity, efficiency, functional and physical readiness, and group communication quality at the forefront.

\subsection{Ethical Issues}

The experiment was carried out in compliance with all ethical standards and anonymity; there were no requirements to provide confidential information (name, surname, age or place of residence, etc.). Also written agreements from the respondents for the conduct and processing of data were received.

\section{RESULTS}

The results are based on the purpose and objectives of the study. Initially, an educational course was developed, the structure of which is presented according to three directions: theory, practice, and creativity (Figure 2). During the course, the following principles were actualized among students: personal and group responsibility, dedication, high-quality interaction, and self-management. Each part of the course had its own concept and was conducted utilizing different platforms. The theoretical part (offered on the basis of the Canvas LMS) was filled with online lectures, videos, and educational information resources. The practical part used the capabilities of Viber and Runkeeper applications and consisted of business cases, role-playing games, and group assignments, where research participants jointly developed solutions to practical problems relevant to modern business. The creative part of the course provided students with the opportunity to show creativity and innovation in solving management problems and share their professional views and ideas via Facebook. At the end of the course, acquired knowledge was tested by means of the Canvas LMS, and the proposed approach to organizing the educational process was evaluated by the students enrolled. 


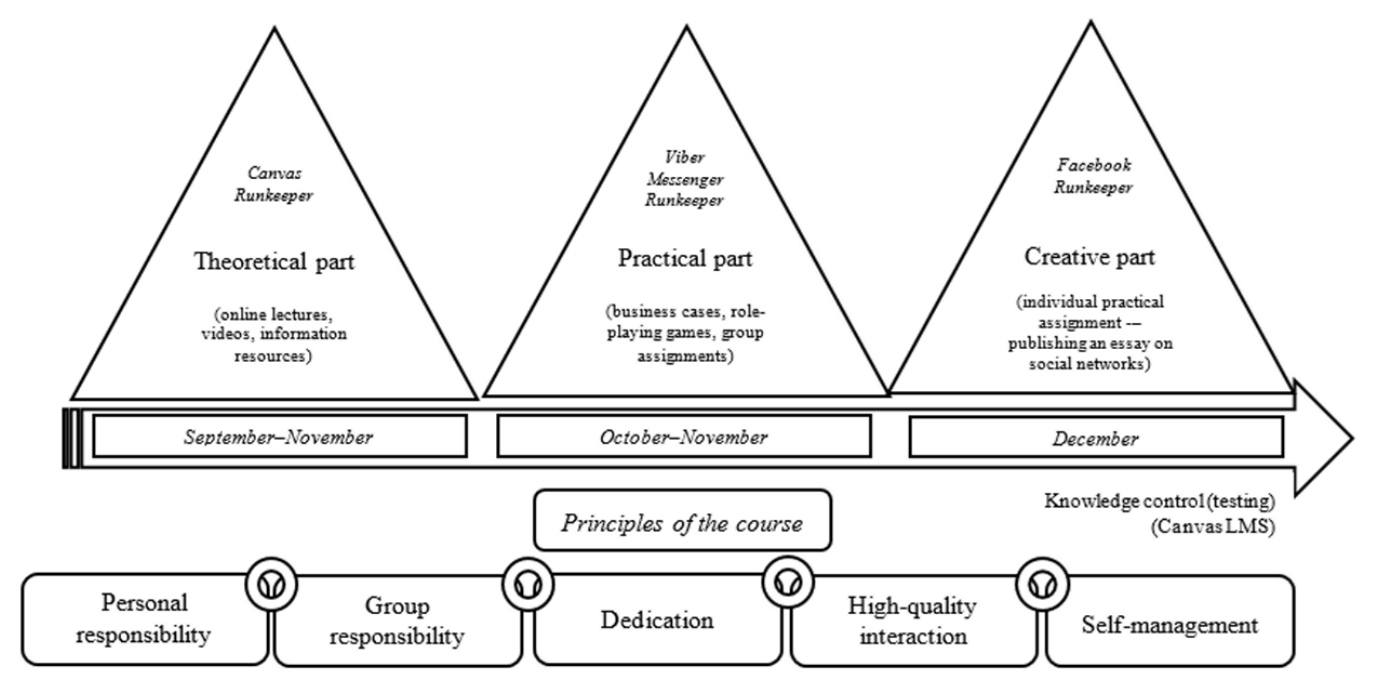

*developed by the authors

The practical part of the course was based on the concept of gamification to increase the efficiency of discussion environments. Its tasks were divided across ten departments of a company with three business cases each to imitate the real organizational structure of a modern firm. For instance, the Strategic Planning Department included business cases demanding management decisions in the strategic business planning segment. For their development, the structure of tasks required collective creativity and mutual cooperation. Hence, the capabilities of the Viber mobile application were used. The task of academic advisers was to lead the discussion to the right topic, monitor each participant's involvement, activity, and effectiveness, as well as record case solutions in a report. At the end of work in one department, a subgroups' transition to the next was carried out. Thus, all students involved had the opportunity to try on the role of managers of Strategic Planning Department, Production Control Department, Procurement Department, Foreign Economic Relations Department, Personnel Management Department, Innovative Development Department, Finance Department, Technology Department, Marketing and Sales Department, Health and Safety Department. Generation of practical management decisions in the structured learning environment provided the possibility to organize effective virtual teamwork and communication (Figure 3).

In order to consolidate theoretical and practical knowledge and skills, students were offered to individually develop comprehensive solutions for businesses of a certain segment with account taken of the modern realities influenced by COVID-19. For this, a separate group was created on Facebook for students to post their essays and share professional views and comments. The training course ended with a test.

Academic advisers evaluated the level of involvement and efficiency of discussion environments during all experiment stages. The results of a comprehensive assessment of the level of compliance and implementation of the educational course principles are presented in Figure 4. This assessment was based on academic advisers' reports and students' surveying results. 
Figure 3. Gamification in the structure of the practical part of the course

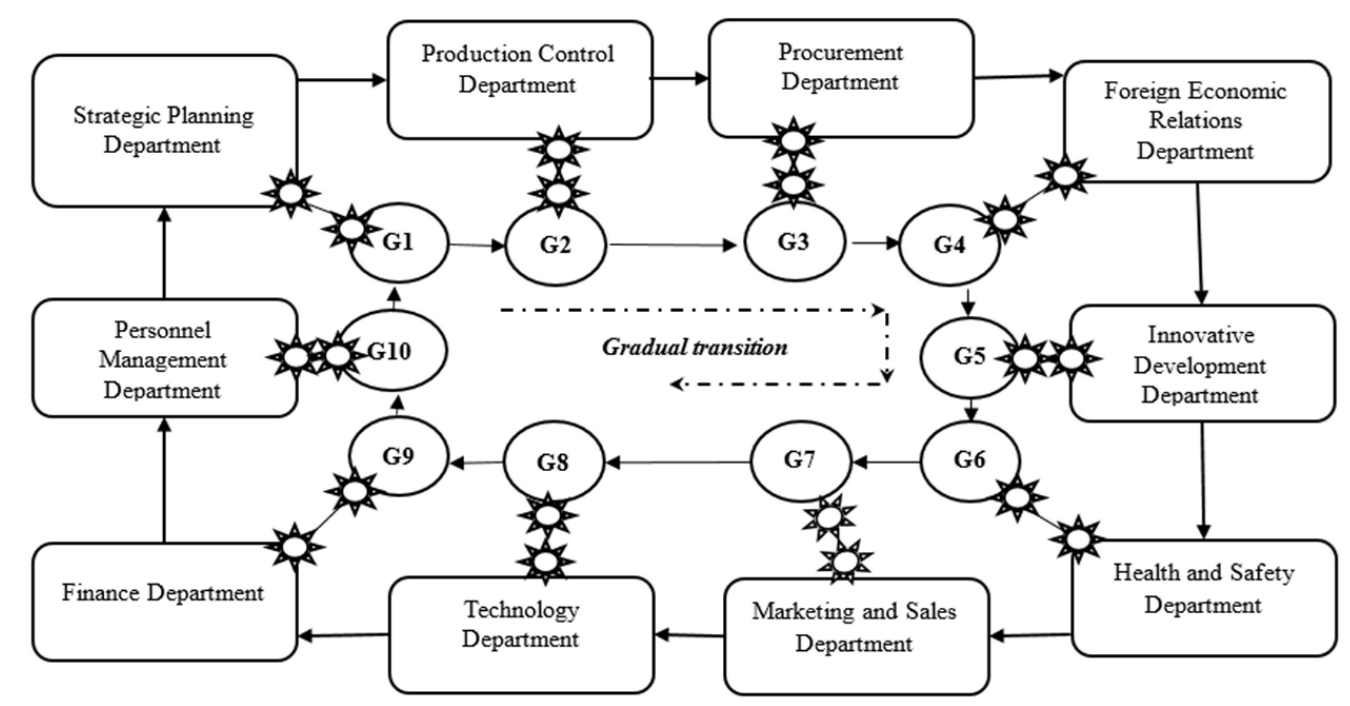

*developed by the authors

Figure 4. Level of compliance and implementation of the educational course principles

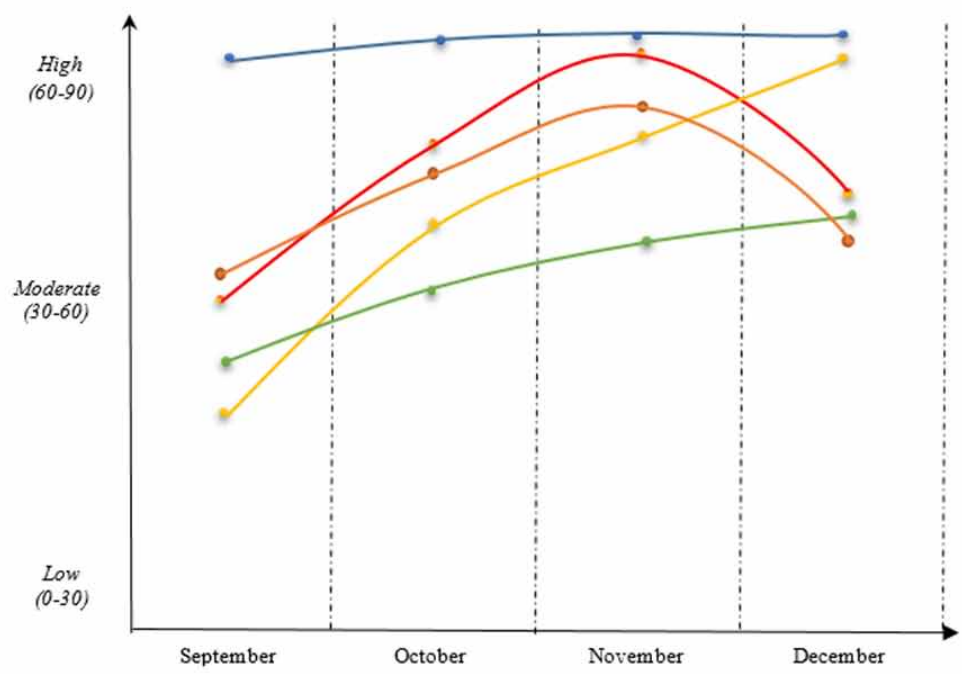

Personal responsibility

Group responsibility
Dedication

High-quality interaction

*developed by the authors

The results show that students' personal responsibility was at a relatively high level throughout the course, at the same time such indicator remained during all experiment and practically did not change. However, the dedication rates were not the same, but changed during the course from medium 
to high. Indicators for other parameters also changed during the course. Accordingly, at the beginning of the course the indicators of group responsibility and high-quality interaction were at the average level, then gradually increased and in November reached a high level. However, after November, the figures fell again to the average level. Indicators on the criterion of self-management were at the average level during the course and varied slightly within this level. The study participants confirmed that the COVID-19 episode and consequences made them reconsider their views on education and take a more responsible attitude towards the educational process than before. At the initial research stage, students' group responsibility and functional readiness were moderate and reached a peak in the third month of study. During the survey, respondents drew a parallel between group responsibility and group assignments and confirmed that the structure of educational practices itself provides for maintaining a high level of responsibility for group interaction and personal self-efficacy. The last month of training was especially notable for a decrease in group responsibility and improvement in dedication level. Study participants associated a high level of dedication with personal aspirations to implement obtained knowledge and experience in practice and the desire to become a sought-after specialist in the current crisis conditions. Even though the level of self-management was remarked as moderate throughout the experiment, students declared absolutely no problems with self-organization, self-motivation, and self-control. Most experiment participants confirmed that the completed online course opened for them a qualitatively new educational experience filled with professional interest, relevance, and efficiency.

The results of the study show that the efficiency of the discussion environment was achieved by the effect of the following aspects:

- Training course structuring, which allowed students to form a clear understanding of educational activities and outline a strategy for the gradual acquisition of professional knowledge and experience;

- Group division, which determined the effectiveness of discussion platforms and made it possible to involve all students in intense learning activity;

- Participants' internationality, which aroused additional interest among students in different views on solving business challenges;

- Using familiar communication tools (Zoom, Viber Messenger, Facebook);

- Updating and promoting the principles of personal and group responsibility, dedication, high-quality interaction, and self-management at all stages of educational activity.

- Conscious attitude to training, which contributed to the formation of a corporate culture of engagement, proactivity, and efficiency in the learning environment.

- Thematic and consulting support, which formed the students' sense of confidence, comfort, and ease in the process of collective solution of practical problems;

- Implementation of business gamification, which gave a boost to the growth of students' interest in practical learning and involvement in educational activities;

- Relevant topic of creative work, which encouraged students to open an innovative view on professional activities and actualized the desire to use the acquired knowledge and experience in practice.

\section{DISCUSSION}

The recent surge in COVID-19 cases has increased panic and anxiety among the student community and raised uncertainty about the normalization of the situation (Kaur et al., 2020). Crises and conflicts not only create chaos in people's lives but pose significant obstacles to education as well. In such moments, many students and teachers face psychological and emotional challenges. The resulting stress, fear, depression, and apathy may lead to an insufficient concentration on one's life and professional activity (Di Pietro, 2018; Kasirer \& Shnitzer-Meirovich, 2021). In this respect, one of the major advantages of online education is that it gives a sense of psychological security against the backdrop of emerging 
risks (Mishra et al., 2020). Unexpected pandemic-related isolation highlights the benefits of being forward-thinking, reflective, and collaborative (Trombly, 2020). Limited communication opportunities caused by COVID-19 afford ground for finding numerous new motivations to work on a continuous basis. Social lockdown appeared to be a new scenario that we have never encountered. Therefore, many students afraid of missing the academic year tend to work harder, which is positively reflected in their academic performance (Gonzalez et al., 2020).

During social distancing, learners should understand their role, form their own attitude and commitment, and find ways to self-motivate to get good educational outcomes. From this perspective, technology management, support from leadership, enhanced awareness of e-learning systems, and adequate digital skills from faculty and students are the most influential determinants in supporting the effectiveness of e-learning during COVID-19 (Alqahtani \& Rajkhan, 2020).

Social networks and mobile applications can considerably improve the system of educational communication, allowing synchronized and non-synchronized interaction in the educational group. Chat rooms, virtual communities, social networks, wikis, blogs, or video-sharing websites have become focal points of the learning environment that bring interaction to another dimension (Denizalp \& Ozdamli, 2019). They allow students to become a part of an online academic environment, create and share content, opinions and achievements, as well as be in touch with each other. Students view social media as a useful learning tool precisely due to its interactive and motivating effect. Proper management of social media tools can positively impact three key learning outcomes: knowledge, skills, and attitudes (Orús et al., 2016).

To increase the effectiveness of modern online education, students should pay more attention to various educational applications. In turn, faculty are recommended to provide simple and engaging study materials that drag the attention of learners towards the digital format of interaction (Soni, 2020). Online courses should be more dynamic, interesting, and interactive. Substantial efforts should be made to humanize the learning process to the best extent possible. The power of digital technology and personal attention are the central factors able to facilitate students' easy adaptation to the new learning environment (Dhawan, 2020). At the same time, it should be borne in mind that students' motivation to use technology does not always translate into more effective learning, particularly if the use of technology and the desired learning outcomes are not closely aligned (Azevedo et al., 2021). Educators need to consider individual differences when developing training policies to ensure that every student can reach their maximum potential within the proposed learning model (Yucheng et al., 2020).

Learners and knowledge conveyors should understand that training online has both strengths and weaknesses. On the one hand, it can increase the effectiveness of preparing future professionals dramatically, ensure a variety of educational technologies in teaching economic disciplines and special courses, and form a responsible attitude among students to these courses' studying. On the other, under certain conditions, e-learning can significantly diminish the creative nature of preparation, cause problems with students' socialization outside the discussion environment, and weaken educators' influence on students' personal development.

Technological advances offer numerous opportunities for improving the quality of learning but yet may raise new social problems and enhance the risk of the digital divide between those who do and do not have access to potential internet benefits. The prerequisites for harnessing the potential of technological advances vary greatly between and within countries, suggesting that modern changes can exacerbate rather than bridge this digital gap (Jensen, 2018). On top of this, most countries have serious problems with technological infrastructure in rural areas. Consequently, e-learning standards can become a critical issue requiring increased attention (Shahzad et al., 2021). 


\section{CONCLUSIONS}

The results show that the indicators according to the selected criteria changed during the experiment: the dedication rates were not the same, but changed during the course from medium to high. Indicators for other parameters also changed during the course; at the beginning of the course the indicators of group responsibility and high-quality interaction were at the average level, then gradually increased and in November reached a high level and then fall to medium level again; indicators on the criterion of self-management were at the average level during the course and varied slightly within this level.

The basis for developing the course concept and structure was represented by the theory of practice architectures. The experiment highlighted such compulsory principles of successful education as personal and group responsibility, dedication, high-quality interaction, and self-management. Each part of the course had its own concept and was conducted on different platforms - this fact allowed making more accurate judgments on the experiment results. The study process revealed that throughout the course, students' personal responsibility was labeled as high. Research participants asserted that new phenomena in their social and educational activities caused by COVID-19 made them reconsider their views on education and become more responsible in this context than before. Besides, the examination unveiled a considerable increase in the level of students' group responsibility and functional and physical readiness during the first three months of the experiment. Research participants paralleled group responsibility and group assignments and indicated that the developed educational course contributes to high responsibility for group interaction and personal self-efficacy. The last month of training was notable for a drop in group responsibility indicator and an increase in dedication. A high level of dedication was predominantly linked with personal aspirations to use the acquired knowledge in practice and the ambition to become an in-demand specialist. Notwithstanding the fact that self-management was assessed as moderate throughout the training, study participants remarked no problems with self-organization, self-motivation, or self-control. As a result, most students surveyed claimed that this e-learning course opened up a qualitatively new educational experience for them that was filled with professional interest, relevance, and efficiency.

In total, the study authors and academic assistants came up with a conclusion that the efficiency of the discussion environment in the educational process was achieved through the course structuring; group division; participants' internationality; using familiar communication tools (Canvas, Viber Messenger, Runkeeper, Facebook); updating and promoting the principles of personal and group responsibility, dedication, high-quality interaction, and self-management; conscious attitude to training; thematic and consulting support; the method of business gamification; and relevant creative work topics. The practical significance and prospects of further research are based on the possibility of using the developed course not only for students of the Faculty of Economics, but also others. The problematic issue of the effectiveness of modern technologies in modern education and their impact on the discussion environment remains relevant. Also, the results can be used in a comparative analysis of the features of the use of modern technologies among students of different specialties or different countries.

\section{ACKNOWLEDGMENT}

Askadula Sabirov has been supported by the Kazan Federal University Strategic Academic Leadership Program. 


\section{REFERENCES}

Abbas, Z., Umer, M., Odeh, M., McClatchey, R., Ali, A., \& Farooq, A. (2005). A semantic grid-based e-learning framework (SELF). In CCGrid 2005. IEEE International Symposium on Cluster Computing and the Grid, 2005 (Vol. 1, pp. 11-18). IEEE. doi:10.1109/CCGRID.2005.1558528

Adarkwah, M. A. (2021). "I'm not against online teaching, but what about us?": ICT in Ghana post Covid-19. Education and Information Technologies, 26(2), 1665-1685. doi:10.1007/s10639-020-10331-z PMID:32952435

Almaiah, M. A., Al-Khasawneh, A., \& Althunibat, A. (2020). Exploring the critical challenges and factors influencing the E-learning system usage during COVID-19 pandemic. Education and Information Technologies, 25(6), 5261-5280. doi:10.1007/s10639-020-10219-y PMID:32837229

Alqahtani, A. Y., \& Rajkhan, A. A. (2020). E-learning critical success factors during the covid-19 pandemic: A comprehensive analysis of e-learning managerial perspectives. Education Sciences, 10(9), 216. doi:10.3390/ educsci10090216

ASICS Runkeeper. (2020). Official web site. Retrieved from https://runkeeper.com/cms/

Azevedo, J. P., Hasan, A., Goldemberg, D., Geven, K., \& Iqbal, S. A. (2021). Simulating the potential impacts of COVID-19 school closures on schooling and learning outcomes: A set of global estimates. The World Bank Research Observer, 36(1), 1-40. doi:10.1596/1813-9450-9284

Basak, S. K., Wotto, M., \& Bélanger, P. (2016). A framework on the critical success factors of e-learning implementation in higher education: A review of the literature. International Journal of Social, Behavioral, Educational, Economic, Business and Industrial Engineering, 10(7), 2409-2414.

Canvas. (2020). Canvas basics guide. Retrieved from https://community.canvaslms.com/t5/Canvas-BasicsGuide/tkb-p/basics

Chien, Y. C., Liu, M. C., \& Wu, T. T. (2020). Discussion-record-based prediction model for creativity education using clustering methods. Thinking Skills and Creativity, 36, 100650. doi:10.1016/j.tsc.2020.100650

Denizalp, H., \& Ozdamli, F. (2019). Determination of student opinions on usage of social media and mobile tools in student-teacher, student-student communication. International Journal of Emerging Technologies in Learning, 14(22), 19-28. doi:10.3991/ijet.v14i22.11745

Dhawan, S. (2020). Online learning: A panacea in the time of COVID-19 crisis. Journal of Educational Technology Systems, 49(1), 5-22. doi:10.1177/0047239520934018

Di Pietro, G. (2018). The academic impact of natural disasters: Evidence from L'Aquila earthquake. Education Economics, 26(1), 62-77. doi:10.1080/09645292.2017.1394984

Facebook. (2020). Official web site. Retrieved from https://www.facebook.com/

Gonzalez, T., De La Rubia, M. A., Hincz, K. P., Comas-Lopez, M., Subirats, L., Fort, S., \& Sacha, G. M. (2020). Influence of COVID-19 confinement on students' performance in higher education. PLoS One, 15(10), e0239490. doi:10.1371/journal.pone.0239490 PMID:33035228

Jensen, U. T. (2018). Does perceived societal impact moderate the effect of transformational leadership on value congruence? Evidence from a field experiment. Public Administration Review, 78(1), 48-57. doi:10.1111/ puar. 12852

Kasirer, A., \& Shnitzer-Meirovich, S. (2021). The perception of creativity and creative abilities among general education and special education teachers. Thinking Skills and Creativity, 40, 100820. doi:10.1016/j. tsc. 2021.100820

Kaur, N., Dwivedi, D., Arora, J., \& Gandhi, A. (2020). Study of the effectiveness of e-learning to conventional teaching in medical undergraduates amid COVID-19 pandemic. National Journal of Physiology, Pharmacy and Pharmacology, 10(7), 563-567. doi:10.5455/njppp.2020.10.04096202028042020

Kemmis, S., \& Edwards-Groves, C. (2018). Understanding Education: History, Politics, and Practice. Springer. doi:10.1007/978-981-10-6433-3 
Mark, G., \& Semaan, B. (2008). Resilience in collaboration: Technology as a resource for new patterns of action. In B. Begole, \& D.W. McDonald (Eds.), Proceedings of the 2008 ACM Conference on Computer Supported Cooperative Work (pp. 127-136). Association for Computing Machinery. doi:10.1145/1460563.1460585

Mishra, L., Gupta, T., \& Shree, A. (2020). Online teaching-learning in higher education during lockdown period of COVID-19 pandemic. International Journal of Educational Research Open, 1, 100012. doi:10.1016/j. ijedro.2020.100012

Muhammad, A., Ghalib, M. F. M. D., Ahmad, F., Naveed, Q. N., \& Shah, A. (2016). A study to investigate state of ethical development in e-learning. International Journal of Advanced Computer Science and Applications, 7(4), 284-290. doi:10.14569/IJACSA.2016.070436

Muralidharan, K., Singh, A., \& Ganimian, A. J. (2019). Disrupting education? Experimental evidence on technology-aided instruction in India. The American Economic Review, 109(4), 1426-1460. doi:10.1257/ aer.20171112

Ngai, C. S. B., Lee, W. M., Ng, P. P. K., \& Wu, D. D. (2019). Innovating an integrated approach to collaborative eLearning practices in higher education: The case study of a corporate communication e-platform. Studies in Higher Education, 44(11), 1990-2010. doi:10.1080/03075079.2018.1482266

Nicolini, D. (2012). Practice Theory Work and Organization. Oxford University Press.

Onyema, E. M., Eucheria, N. C., Obafemi, F. A., Sen, S., Atonye, F. G., Sharma, A., \& Alsayed, A. O. (2020). Impact of Coronavirus pandemic on education. Journal of Education and Practice, 11(13), 108-121. doi:10.7176/ JEP/11-13-12

Orús, C., Barlés, M. J., Belanche, D., Casaló, L., Fraj, E., \& Gurrea, R. (2016). The effects of learner-generated videos for YouTube on learning outcomes and satisfaction. Computers \& Education, 95, 254-269. doi:10.1016/j. compedu.2016.01.007

Rakuten Viber. (2020). Official web site. Retrieved from https://www.viber.com/ru

Rieley, J. B. (2020). Corona virus and its impact on higher education. Retrieved from https://www.researchgate. net/post/Corona_Virus_and_its_impact_on_higher_education

Shahzad, A., Hassan, R., Aremu, A. Y., Hussain, A., \& Lodhi, R. N. (2021). Effects of COVID-19 in E-learning on higher education institution students: The group comparison between male and female. Quality \& Quantity, 55(3), 805-826. doi:10.1007/s11135-020-01028-z PMID:32836471

Sjølie, E., Francisco, S., Mahon, K., Kaukko, M., \& Kemmis, S. (2020). Learning of academics in the time of the Coronavirus pandemic. Journal of Praxis in Higher Education, 2(1), 85-107. doi:10.47989/kpdc61

Soni, V. D. (2020). Global impact of e-learning during COVID 19. SSRN Electronic Journal, 3630073. 10.2139/ ssrn. 3630073

Talan, T. (2020). The effect of mobile learning on learning performance: A meta-analysis study. Educational Sciences: Theory and Practice, 20(1), 79-103. doi:10.12738/jestp.2020.1.006

Trombly, C. E. (2020). Learning in the time of COVID-19: Capitalizing on the opportunity presented by the pandemic. Journal of Professional Capital and Community, 5(3/4), 351-358. doi:10.1108/JPCC-05-2020-0016

Vorbach, S., Poandl, E. M., \& Korajman, I. (2019). Digital entrepreneurship education: The role of MOOCs. International Journal of Engineering Pedagogy, 9(3), 99-111. doi:10.3991/ijep.v9i3.10149

Yucheng, J., Bohan, J., Nanzhi, W., \& Jiayi, S. (2020). Covid-19 and behavioural changes in students' learning patterns and efficiency. Frontiers in Educational Research, 3(10), 21-27. doi:10.25236/FER.2020.031004

Zhigareva, O. G., Yurchenko, A. L., Skrygin, S. V., \& Goryacheva, M. V. (2019). Mobile applications and physical activity registers: User portraying study. Theory and Practice of Physical Culture, 11, 40-42. 
Askadula Sabirov was born 24.05.1954. 1971-1976 he got higher education in Kazan state university, historical and philological faculty, history, History. His qualification is Historian. Teacher. Academic degrees - doctor (philosophical sciences) (09.04.1998), speciality 09.00.11 - Social Philosophy, thesis title "Subject formation and institutionalization of social and philosophical anthropology in modern society". Academic Titles: Professor (21.04.1999).

Fariza Ismagambetova is Master of Arts in Economics, PhD student, Computer Science in L.N. Gumilyov Eurasian National University. Skills and Expertise: Pedagogy and Education, Education Research, Teaching and Learning, Curriculum Development, Instructional Design, Online Learning, Technology Enhanced Learning, Professional Development, Teacher Education.

Alexander Yurchenko is Ph.D. (pedagogic), Associate professor, Physical education in Financial University under the Government of the Russian Federation. Skills and Expertise: Teaching and Learning, Pedagogy, Pedagogics, Student Development, Pedagogy and Education, Professional Development, Online Learning, Adult Learning and eLearning in Higher Education. 